\title{
Techno-legal entanglements as new actors in the policy-making process
}

\author{
Francesco Gualdi \\ London School of Economics and Political Science \\ F.Gualdi@1se.ac.uk
}

\author{
Antonio Cordella \\ London School of Economics and Political Science \\ A.Cordella@1se.ac.uk
}

\begin{abstract}
The mechanisms by which Information and Communication Technologies (ICTs) support public sector reforms have been widely studied in $e$ government literature. This paper contributes to this literature analyzing how the entanglement of law and technological systems shapes the trajectory of policymaking. The paper discusses the case of the policymaking which led to the approval of changes in key articles of the Italian Digital Administration Code $(D A C)$. The paper contributes to the e-government literature highlighting that the policy-making choices and options are constrained by how previous law and technology have been entangled to support the digitalization of the public administration. The paper provides valuable insights to better understand the impacts associated with the digitalization of the public administration, specifically of legal norms and procedures, on policy-making processes.
\end{abstract}

\section{Introduction}

Information and Communication Technologies (ICTs) play a key role in the modernization of the public administration. Public sector reforms rely on ICTs to promote efficiency and effectiveness of public policies [1-4].

Technology impacts on public administration have been studied in their effects on the quality and quantity of the provision of public services $[5,6]$, but also in the effects on the different values carried by the policies which informed the design and deployment of ICT in the public sector $[7,8]$. Research has also focused on how law and technology entangle and on the mechanism by which these entanglements shape the public policies informed by that law $[9,10]$.

Policy-making processes, stemming from the definition of a policy goal, result in the drafting of new legal norms, codes, or frameworks which regulate what a policy is, how it applies and to whom it applies, when approved by the parliamentary process [11].
Policy-making is therefore closely linked to the law-making process [12]. Pre-existing techno-legal entanglements affect the law-making process and hence the policy-making process. The paper sheds light on these complex processes and offers new insights to better understand the nature and magnitude of the impacts of technology on the public sector and more specifically on policy-making processes.

The paper is structured as follow: section two illustrates the relevant literature investigating the negotiations of law and technology. Section three accounts for the impacts of techno-legal entanglements on policy-making process. Section four introduces the theoretical framework of functional simplification and closure. Section five explains the methodology followed in this paper. Section six presents the case of the Italian DAC reform. Section seven provides an explanation of techno-legal entanglements emerging from the case study. Section eight discusses the main findings from the case study. Section nine illustrates the conclusions of the paper.

\section{Background}

The complex nature of the negotiations between law and technology and their impacts on society have been researched by scholars in different domains. Scholars in law have mostly studied the impacts of technology adoptions on the way in which judicial decisions are taken and their impacts on society [13-15]. A good example of this tradition is the work by Reed and Murray [13] which concentrates on how authority, control and legitimacy apply to the cyberspace, going beyond the traditional law domain. Scholars in philosophy have mostly analysed the ethical implications associated with the legalization of the most advanced technologies [16-18]. Mittelstadt and Floridi [18] offer interesting findings on the regulations of Big Data in biomedical and health sectors. In the field of Information Systems, the entanglements between law and technology have been studied mainly looking at how the code of the technology negotiates with the code of the law $[9,19]$. In particular, the research by Lanzara 
[19] sheds light on the way by which technological systems have profoundly impacted procedures and tasks in the field of e-justice. Despite an increasing aim to bridge the domains of law and technology, the call for "an interdisciplinary tradition of law and technology" [20] has mostly gone unheard. Significant exceptions to this trend are Brownsword [21], Hildebrandt [22, 23], Mohr and Contini [24], who explore the way by which technology and law in their entanglements define new techno-legal institutional and organizational environments whose specific characteristics are not fully explained yet.

The emergence of these techno-legal entanglements raises several questions about the nature of the formal and informal mechanisms that shape institutional and organizational relations and contexts. To analyse these mechanisms, scholars have investigated how the regulative properties of law and technology negotiate when they are deployed to regulate the same mechanisms which govern organizational or institutional relations and contexts.

The regulative properties of law are widely recognized and acknowledged, and to some extent even intuitive: law is designed and deployed to alter the behaviours of others with the intention of producing an outcome [23]. In other words, law has a normative purpose, which is to define what is legal and what is not [24]. Law boundaries are distinctly demarcated: it is always clear who are the regulators and who are the subjects of regulation, what is regulated, when and how is it possible to challenge what is regulated by the law. Also, even when the law produces ambiguities - since law presupposes interpretation - the patterns to adjust and modify the regulative properties of the law are clear and formalized in the law [24].

The boundaries of the regulative properties of technology are not equally demarcated. Technology is inherently multistable [23]: its structures are often loosely connected [25], and the reproduction of technological outcomes follows patterns of generativity [26] which makes almost impossible to anticipate and predict its regulative impacts. Platforms and Artificial Intelligence, for example, generate externalities [27] and create opacity [28] which are not under the direct control of the designers or the users [28-30]. Therefore, these technologies result in regulative regimes that are neither accountable nor intelligible from the perspective of policymakers.

Technology works according to the codes and scripts it contains, which are different from the norms enclosed in any legal act. Scholars have accounted for the ways by which technology and law negotiate their regulative properties in formal configurations [19] which result in techno-legal entanglements. Techno-legal entanglements have very specific regulative characteristics which impact organization and institutional actions. Techno-legal entanglements govern the organizational contexts due to a combination of existing logics already in place (norms, legal prescriptions, regulations) and technological properties. These entanglements are regulative in the sense that, once adopted, they re-structure the activities of the workflows and set or span the boundaries of the activities. However, the combination of technological and legal domains is not an easy task to achieve. Often, techno-legal entanglements have composite nature and produce unpredictable outcomes following unstable trajectories [19]. For this reason, a nuanced account of the impact of techno-legal entanglements in policymaking processes is necessary.

\section{Law, technology, and policy-making}

Policy-making consists of a process which includes three main phases: (a) deciding the policy, (b) producing the legislative clauses (law-making), (c) handling Parliamentary process [11]. Many different actors concur to shape policy-making: members of the government, Members of Parliament (MPs), civil servants, experts involved in the activities [11]. All these actors can be defined policymakers. When technologies intertwine with the law-making process new challenges emerge for the policymakers. The policy-making is transformed from a law-making process into the design of a techno-legal entanglement where law and technology negotiate their regulative regimes. Since the nature of these regulative regimes is a complex balance, the unfolding of techno-legal entanglements shall be careful monitored (a) to avoid outcomes which contrast with the drivers of the policymaking process, and (b) to oversee that the regulative outcomes remain within the boundaries of democratic and constitutional principles.

Research has shown that the impact of technology might put at risk the outcome of legislation if policymakers are not aware of the very specific characteristics of technology [24, 31]. For example, Bovens and Zouridis [32] have illustrated that technology used to deploy public policies carries regulative powers that impact and potentially change what is regulated by constitutional norms and democratic principles. In their view, technology contributes to the definition of a regulative regime which cannot be easily reconducted within the boundaries of constitutionality [32]. Any adoption of technological instruments that regulate the functioning of the public sector carries risks of undermining the legitimacy of our society [32].

Building on this research tradition, this paper aims to make a step forward by shedding light on the way by 
which technology transforms not only the implementation of policies which are the outcome of the policy-making process, but the policy-making process itself. In this paper we explore how technology creates the conditions to fundamentally alter the procedures and patterns which regulate the design, drafting, discussion and approval of an act with the force of law and hence the policy shaped by that law. The paper offers theoretical contribution to the study of law and technology by showing that technology modifies the policy-making process having an impact on the underpinning law-making process. By so doing, technology acts with the authority of a constitutional force which is not foreseen in any legal environment. Hence, the constitutionality of these techno-legal entanglements needs to be carefully investigated by scholars and adequately acknowledged by policymakers and practitioners.

\section{Theoretical Framework}

To understand how technology impacts on the policy-making process we rely on the theory of functional simplification and closure. This theory explains how technological artefacts carry regulative properties [33, 34] which transform the policy-making process. This literature builds on Luhmann's seminal work, whose research has illustrated the specific technological properties that impact and modify interactions in the environments where technology is adopted [35]. Organizations deploy technological systems to improve the execution of specific workflows. Technological systems to operate must receive inputs and produce outputs. Inputs to be processed by the technology need to be formatted in a way (language) which is comprehensible by the technology to generate its outputs. To be able to process information from the external context, technological systems have to reconstruct in the code of technology the practices and actions proper of organizations [33] in a language which is understandable by the technology. To do so, technology frames activities and practices from the external world in a language that is readable by software. When technology processes these inputs to produce outputs it also does so in the way standardized in the code of the used software or technology. The outputs are the result of stable and standardized interactions designed in the code of the software / technology [33]. Luhmann described these transformations as generated by specific properties of technology: functional simplification and closure [35]. Functional simplification is the process by which technology reduces (or simplifies) the causal connections of the external world in a way which is understandable by the code of technology [35]. In other words, all the practices and activities of a specific environment are encapsulated in logical sequences which constitute the core of any technological artifact.

The reconstruction of activities and practices in the code of technology would not be possible without a parallel process of functional closure. Functional closure is the isolation of the set of causal connections from the context, to prevent the context (namely, processes and actors) to intervene on the technological execution, and to allow technology to replicate practices and activities. The properties of functional simplification and closure allow technology to frame normative, behavioural, and legal logics which shape organizational contexts, and to reproduce them according to technological standards.

This theory sheds light on what happens when technological systems functionally simplify and close practices and activities: they change their nature, because the processes of functional simplification and closure modify forever their original characteristics. Consequently, the new causal connections, rewritten in technological frames and stabilized, have the authority to impact and modify organizational tasks and workflows. Since technological systems are increasingly adopted in organizations to improve the execution of tasks and activities, technology has the ability to profoundly alter the underpinnings of complex organizations. This can be true for cultural and social norms, but it is also true for more formalized elements, such as institutions and legal norms.

\section{Methodology}

To discuss how the regulative power of technology impacts the policy-making process, we rely on a case from the Italian parliament ruling on the Codice dell'Amministrazione Digitale (DAC - Digital Administration Code). The paper follows the case study research approach [36] since it aims to investigate a phenomenon within its context [37]. In addition, the case study approach offers relevant insights when the boundaries between a phenomenon and a context are not clear [36]. Since we account for the ways by which technology impacts upon the policy-making process, we need a nuanced evaluation of the actions taking place along the different phases which structure the lawmaking process.

Building on Yin's taxonomy, we adopt the explanatory case study approach [36] because it is suitable to explain how a single factor (technology adoption) impacts a specific practice (the policy-making process). The explanatory case study approach is relevant when the outcome of a process is straightforward and we can concentrate on the analysis of the reasons that explain the outcome [37]. The case 
of the Italian parliament passing the law that reforms the DAC is exemplificative to account for the way by which technology impacts the policy-making process. Data collection consists of qualitative data which includes three types of sources: (a) official transcripts from the Italian Parliament Committees sessions which discussed the drafting of the regulations; (b) primary sources of law and government documents; (c) secondary sources such as analysis, commentaries, and opinions from professionals of the judicial sector. Table 1 illustrates the documents consulted.

Table 1. List of documents consulted

\begin{tabular}{|c|c|c|c|}
\hline Subject & Name of document & Type of document & Date(s) \\
\hline DAC & Legislative decrees $82 / 2005,235 / 2010,179 / 2016,217 / 2017$ & Primary legislation & \\
\hline Civil Trial & Decrees-Law: 24/2010, 221/2012, 114/2014, 132/2015 & Primary legislation & \\
\hline Online & Ministry of Justice Decree 21 February 2011, n. 44. & Secondary legislation & $21 / 2 / 2011$ \\
\hline DAC & Chamber of Deputies Committee on Constitutional Affairs minutes & Official transcript & $23 / 6,2-3 / 82016$ \\
\hline Legislative & Chamber of Deputies Committee on Budget minutes & Official transcript & $21 / 7,26 / 72016$ \\
\hline \multirow[t]{9}{*}{ Process } & Joint Committee on Simplification minutes & Official transcript & $20 / 7,27 / 72016$ \\
\hline & Senate Committee on Budget minutes & Official transcript & $1-3 / 82016$ \\
\hline & Senate Committee on Finance and Treasury minutes & Official transcript & $19 / 7,27 / 72016$ \\
\hline & Council of State advisory opinion & Formal opinion & $17 / 3 / 2016$ \\
\hline & State-Regions Conference advisory opinion & Formal opinion & $3 / 6 / 2016$ \\
\hline & Regions and Provinces Conference advisory opinion & Formal opinion & $3 / 6 / 2016$ \\
\hline & Union of the Provinces advisory opinion & Formal opinion & $3 / 6 / 2016$ \\
\hline & Data Privacy Authority advisory opinion & Formal opinion & $9 / 62016$ \\
\hline & Chamber of Deputies Report attached to Government Act 307 & Report & \\
\hline
\end{tabular}

\section{Case study}

Over the years, the Italian government has repeatedly attempted to reform the Public Administration by leveraging on ICTs. The launch of the DAC in 2005 provide to most relevant attempt to define a single legal framework for the digitalization of the public sector.

\subsection{Digital Administration Code (DAC)}

Since the deployment of DAC in 2005 that Italian policymakers had to intervene several times to update the legal architecture of DAC. Italy is a civil law-based system. Since technological specifications are part of the DAC bill, the policymakers needed to adopt every single modification of DAC with a formal bill or regulation. Both the Parliament and the Government concur to discuss and design the changes in the legislation on DAC.

The aim of the DAC is to regulate all the aspects of the digital transformation of the public sector. The DAC equally frames the digitalization norms across different branches of the public bureaucracies and on the relationship among public administration, business, and citizens.

The DAC bill is not the only regulative framework which frames the digital transformation of the Italian public sector. Many public sector organizations, such as
Ministries, agencies, public bodies, had built their own ICT systems and drafted normative codes to digitize tasks and processes. Accordingly, when the DAC was introduced, the Italian policymakers had to align the DAC dispositions about ICT with those already in place across the Italian public sector organizations. A misalignment among different sources of law such as between DAC and ministerial normative codes could in fact originate legal ambiguities and generate organizational drawbacks. Furthermore, misalignment in regulations designed to enable IT systems could produce further disadvantages. Many public organizations had their own IT systems, carefully designed, and crafted to execute specific tasks which could not be executed had the system not be supported and enable by the DAC regulative legal framework.

When systems were not supported by DAC public managers raised concerned and doubts about the possibility to adapt or transform their IT systems to comply with the DAC regulative framework.

The policymakers responsible to maintain the DAC regulations updated discovered that there were resistances to the general application of DAC across all the Italian public administration. The most challenging case has been the conflict between the DAC regulative framework and the norms which regulate the Processo Civile Telematico (Civil Trial Online - CTO). 


\subsection{Civil Trial Online (CTO)}

The Civil Trial Online (CTO) modernizes the civil branch of justice through the adoption of ICT. The CTO is the outcome of multiple legislative acts. This corpus of laws encompasses primary and secondary sources of law (including ministerial regulations and technical specifications) and stratified customs.

Specifically, the two main primary acts which organize, and structure CTO are laws 24/2010 and $221 / 2012$. The secondary acts are less relevant in terms of juridical hierarchy, yet still important: the ministerial decree 44/2011 sets the guidelines, while the technical specifications attached to the decree (Act 16 April 2014) define the required characteristic for technological instruments.

\subsection{The reform}

In 2016 and 2017 Italian Parliament approved two legislative decrees - bills - to modernize the DAC (legislative decrees 179/2016 and 217/2017). The legislative decree is a very specific type of bill, inspired by the government under a Parliamentary mandate. The mandate clearly determines the boundaries of what the government can cover in the legislative decree. The Government receives a formal mandate by the Parliament to produce a draft legislative decree. The decree is then submitted to the Parliament for approvals. The Parliament examines and assesses the decree within 60 days. Usually, the decree is first discussed by the relevant parliamentary Committees which provide feedback to the Government before the decree is voted by the Parliament. The Government might consider the committees' recommendations, but it has no obligation to do so before submitting the decree to the Parliament vote.

In relation to the legislative process concerning decrees 179/2016, Parliament's Committees held multiple discussions to produce an informed opinion to be submitted to the Government.

In 2016, when Committees began the examination of government's draft legislative decrees 179/2016 (Government Act 307), MPs became aware of one potential problem. Two specific articles of the act drafted by the Government - art. 2.6 and 18.1 - aimed to change how the DAC regulations applies to civil and criminal law trials.

The preexisting version of DAC (Article 20, "Validity and effectiveness of the electronic document as evidence") provided technical specification for electronic document to be automatically considered valid evidence in trials; leaving to the judge the discretionarily to admit electronic documents which do not fulfill the DAC technical specification as pieces of evidence.

The article 2.6, and 18.1 of the Government Act 307 transform the effectiveness of the existing DAC Article 20. Article 2.6 stated that:

"The provisions of this Code shall also apply to civil and criminal trials, insofar as they are compatible and unless otherwise provided by the provisions on civil trial online."

While article 18.1, stated:

"The provisions concerning the electronic filing of acts and documents in accordance with the legislation, including regulations, of Civil Trial Online shall remain in force".

While article 2.6 is a general disposition, article 18.1 is very specific and aims to maintain a special provision for the e-filing of electronic documents. The Ministry of Justice's Decree 44/2011 and technical disposition produced by the Ministry of Justice in April 2014 defines the e-filing procedure of electronic documents in CTO. The Decree and the technical dispositions define what an "electronic document" is in relation to the CTO: what characteristics it must have, and how to handle the electronic document in each phase, from production to transmission, from filing to storage.

The outcome of the joint formulation of articles 2.6 and 18.1 is that the CTO procedures were excluded from the domain of application of DAC. Since this was a formulation explicitly mentioned in the decree drafted by the Government, it witnessed a clear aim to create two distinct regimes - one set by the rules of CTO, and the other one organized according to DAC dispositions. In other words, the CTO acquired a status of exceptionality in comparison to the other digitalized procedures, ruled by DAC.

\subsection{Parliament's Committees assessment of Government Act 307}

Following the procedure for the approval of the Legislative Decree 179/2016, the Parliament was required to provide an advisory opinion about the Act 307 drafted by the government. Several Committees were involved in this process: Committee for Constitutional Affairs and Budget of the Chamber of Deputies; Committee for Constitutional Affairs, Budget and Finance and Treasury of the Senate; and the Joint Committee for Simplification.

The analysis of the Committees sessions transcripts shows that the Committee for Constitutional Affairs of the Chamber of Deputies held the liveliest debate articles 2.6 and 18.1. Regarding article 2.6, the Committee proposed to expand the application of DAC to all type of trial Act 307 only referred to civil and criminal trials. The Committee wanted to guarantee the 
application of DAC “ (..$)$ to every trial before a judicial authority, unless otherwise provided by the provisions of Civil Trial Online".

The Committee also asked the government to cancel art. 18.1 ("The provisions concerning the electronic filing of acts and documents in accordance with the legislation, including regulations, of Civil Trial Online shall remain in force"). The Committee believed that this disposition exceeded the powers of the government. In fact, the provision could potentially create a special regime for the CTO, outside of the DAC domain. In the view of the Committee this fell outside the boundaries of the mandate the Parliament gave to the Government.

The Budget Committee of the Chamber of Deputies focused mostly on the economic sustainability of the reform and did not raise any issue about its content.

The Senate's Committees, building on an advisory opinion from the Italian Council of State ${ }^{1}$ released on April 2016, criticized the formulation of article 2.6 advocating for an extension of the DAC applicability. Accordingly, Senate's Committee for Constitutional Affairs asked the government to explicitly include administrative, tax and accountancy trials references in article 2.6. The Committee didn't present any specific comment on article 18.1. The Senate's Budget Committee didn't express any concern on the issue.

Finally, the work carried out by the Joint Simplification Committee was relatively limited, with an opinion that produced one observation on article 2.6. The Committee insisted on the need to extend the applicability of DAC to civil and criminal trials "in order to increase the homogeneity to the regulative framework". The Joint Simplification Committee relied on the Council of State's opinion and echoed the Senate's Committee for Constitutional Affairs.

A summary of the assessment of the draft legislative decree (Government Act 307) in the competent committees can be found in Tables 2 and 3 .

Table 2. Assessment of the Government Act 307 in the Chamber of Deputies' Committees

\begin{tabular}{|c|c|c|c|}
\hline Committee & Sessions & Observations on art. 2.6 & Observations on art. 18.1 \\
\hline \multicolumn{4}{|l|}{ Constitutional } \\
\hline \multirow[t]{3}{*}{ Affairs } & 2362016 & None & None \\
\hline & 0282016 & $\begin{array}{l}\text { The Committee proposes to amend article } 2.6 \text { to } \\
\text { ensure the application of the provisions of the DAC } \\
\text { "to any trials before a judicial authority, unless } \\
\text { otherwise provided by the provisions on telematic } \\
\text { process" (remark } c \text { ). }\end{array}$ & $\begin{array}{l}\text { The committee asked the Government to delete from } \\
\text { Article 18.1, paragraph c, the words "The provisions } \\
\text { concerning the electronic filing of acts and documents } \\
\text { in accordance with the legislation, including } \\
\text { regulations, of CTO shall remain in force" (remark } m \text { ). }\end{array}$ \\
\hline & 0382016 & None & None \\
\hline \multirow[t]{2}{*}{ Budget } & 2172016 & None & None \\
\hline & 2672016 & None & None \\
\hline \multicolumn{4}{|l|}{ Joint } \\
\hline \multirow[t]{2}{*}{ Simplification } & 20072016 & $\begin{array}{l}\text { The rapporteur sheds a light on the need to extend the } \\
\text { applicability of the DAC to civil and criminal trials. } \\
\text { He then formulates a proposal for an observation that } \\
\text { makes explicit "in Article } 2.6 \text { of the draft, that it also } \\
\text { refers to administrative, accounting and tax trials, to } \\
\text { make the regulative framework more homogeneous". }\end{array}$ & None \\
\hline & 27072016 & $\begin{array}{l}\text { Opinion is approved in line with rapporteur's } \\
\text { remarks. }\end{array}$ & None \\
\hline
\end{tabular}

Table 3. Assessment of the Government Act 307 in the Senate's Committees

\begin{tabular}{|c|c|c|c|}
\hline Committee & Sessions & Observations on art. 2.6 & Observations on art. 18.1 \\
\hline \multicolumn{4}{|c|}{ Constitutional } \\
\hline \multirow[t]{3}{*}{ Affairs } & 29062016 & $\begin{array}{l}\text { The rapporteur addresses article } 2.6 \text { without going } \\
\text { into the relationship between CTO and DAC. }\end{array}$ & $\begin{array}{l}\text { The rapporteur addresses article } 18.1 \text { without going into } \\
\text { the relationship between CTO and DAC. }\end{array}$ \\
\hline & 12072016 & None & None \\
\hline & 27072016 & $\begin{array}{l}\text { The rapporteur suggests incorporating the following } \\
\text { recommendation: "Secondly, in Article } 2.6 \text {, which } \\
\text { accounts for the application of the DAC to civil and } \\
\text { criminal trials, insofar as they are compatible and } \\
\text { unless otherwise provided for in the rules on Civil }\end{array}$ & $\begin{array}{l}\text { The rapporteur addresses Article } 18 \text { but does not insist } \\
\text { on the CTO's exemption from the DAC. The same from } \\
\text { the MEPs who speak about Article } 18 \text {. } \\
\text { The general focus is on the characteristics of advanced, } \\
\text { qualified, or digital electronic signatures. }\end{array}$ \\
\hline
\end{tabular}

${ }^{1}$ The highest authority of administrative justice 
Trial Online, it would be appropriate to include an and tax proceedings, in order to make the regulative framework more homogeneous", as suggested by the Council of State.

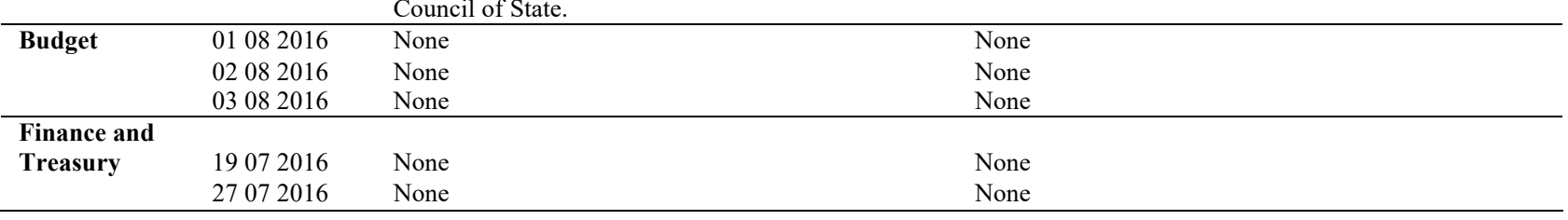

A government representative who is attending the Committee's session, reiterated that the government does not want to amend Article 18. explicit reference also to administrative, accounting

The discussion within the Parliamentary Committees shows that MPs expressed concerns about the formulation of the two key articles of the Government Act.

The Government decided to partially accept only the new proposed formulation of article 2.6 made by Senate's Committee for Constitutional Affairs. In the final version proposed by the Government article 2.6 reads: "The provisions of this Code apply to civil, criminal, administrative, accounting and tax trials, insofar as they are compatible and unless otherwise provided by the provisions on Civil Trial Online". The government wanted to maintain the special regime for CTO, but also agreed to extend the application of DAC to other types of trials. The Parliament approved the final version proposed by the Government on 26 August 2016. The analysis of different sources Committees' sessions minutes, comments and opinions by experts and professionals - reveals that the decision of the government to reject the comments and recommendation of the committees and to push for the approval of the version which grants the CTO a special regime outside the DAC is determined by the techno-legal entanglement which shapes the CTO and make it de facto incompatible with DAC.

\section{CTO: a techno-legal entanglement}

The CTO to be effective needs the development of different technological solutions. Fundamental requirements are the deployment of a Case Management System (CMS) and of an e-filing system. The CMS provides the backbone of the court digital functionalities while e-filing consists of the front office technology which structures and support the exchange of procedural documents online. The development of a CMS and of an e-filing system requires both technological and legal compliance. To be effective the two systems need to be able to fully integrate. They shall be designed to provide full technological, semantic and legal interoperability [9]. E-filing systems need to be able to smoothly exchange documents with the Case Management System, in a way which guarantees that the exchanged documents are in the format prescribed by the law and containing the information also prescribed by the law.

The design of the e-filing system is the result of a negotiation process between what is required by the technology to support interoperability and what is prescribed by the law to guarantee legal compliance with the procedural codes (document formats, email protocols and standards, digital signature encryption, data transmission protocols and standards). The negotiation was long and complicated, and it required many changes in the law and in the technology [38]. Eventually, designers managed to achieve a successful alignment of technological specification with the legal code, but it was also necessary to foster changes in the legal code to align with technological requirements. After almost 15 years of techno-legal negotiations, this system resulted in a sustainable and successful technolegal entanglement able to fully support the needs of the CTO and lead to its successful deployment and use [38]. Article 18.1 if amended as requested by the parliament would have put at risk the effectiveness of the e-filing techno-legal entanglement and hence of the CTO.

\section{Discussion}

The Government turned down the request to revise the formulation of article 18.1 and decided that the electronic filing of acts and documents, at the core of the CTO, should be granted a special regime instead of aligning to DAC provisions. CTO regulations on the electronic document represents a cornerstone of the way by which trials take place in Italy. All the actors involved in the civil trials - lawyers, judges, clerks must follow CTO regulations on electronic document filing (the format of the document, the transmission, the collection, the signature), otherwise they risk invalidating the trial or to lose the legal dispute. The efiling norms and technologies were in place since 2011, the technology which functionally simplified and closed the e-filing process defined the regulative regime governing the e-filing procedures. Daily 
activities such as notifying an act, uploading materials in pdf format, digitally signing a document, have become formalized in the e-filing technologies. The entanglements of formal norms and technology shaped the way by which tasks and procedures are executed in civil courts. Against this background, the amended version of article 18.1 of the DAC regulation would have introduced a new regulative regime for the CTO, which is not compatible with the existing techno-legal entanglements which govern e-filing and hence the CTO. The government had to protect the CTO's techno-legal entanglement to preserve the effectiveness of the CTO proceedings. By rejecting the application of changes that would have extended the DAC to CTO, the government aimed to safeguard the techno-legal systems that renders valid and effective the transactions that must be carried in a CTO proceeding [39]. As explained by Petrucci [40], the choice to exclude CTO from DAC stemmed from the willingness to limit the difficult reconciliation between general-specialist regulations (the DAC), super-specialist regulations (the CTO Regulations), which conflict on how to regulate the same legal proceeding and, in particular, the electronic document and its transmission and storage. Experts also noted that the Italian government acted to avoid the repetition of a mistake made in 2015, when a collision between DAC norms and CTO put at risk the effectiveness of CTO proceedings [41]. This can explain why with article 18.1 the government acted with caution and respect, to avoid the controversy over the legal and technological specifications of the digital document that emerged at the beginning of 2015, when the DAC put the CTO on its knees, changing the format and procedures with regards to the forms of to be used in e-filing [41].

The decision of the government to reject the proposal of changing or withdrawing article 18.1 was dictated by the nature of the existing techno-legal entanglement which shapes the regulative regime of efiling and hence of CTO. The government's choices in the drafting of the policy designed in the amended regulation of DAC to give special regime to the CTO, also overruling the parliamentary concerns with regards to legitimacy of such an act, was dictated by the e-filing techno-legal entanglement. The technolegal entanglement, de-facto, constrained the policymaking process determining what could be designed in the revised version of DAC and what could not be changed by DAC. The existing techno-legal entanglement, de facto, became the key actor which shaped the DAC policy overtaking government and parliamentary authority and legitimacy.

\section{Conclusions}

The impact of technology on the application of law and policies has been discussed by scholars in many different domains. E-government scholars have also discussed how technology carries political power [32, 42]. In this paper we complement this research discussing how technology shapes legal norms and regulation into techno-legal entanglement and how this techno-legal entanglement constraint the policymaking process. We draw our conclusions building on the analysis of the legislative process which led to the design and approval of changes in the Italian core legislation which governs the digital administration. The case reveals that the techno-legal entanglement which shaped the CTO limited the policy-making options and hence the definition of a unique and integrated document exchange format across the Italian public administration.

\section{References}

[1] J.C. Bertot, E. Estevez, and T. Janowski, "Universal and contextualized public services: Digital public service innovation framework", Government Information Quarterly, 33 (2), 2016, pp. 211-222.

[2] A. Meijer, "Why don't they listen to us? Reasserting the role of ICT in Public Administration", Information Polity, 12 (4), 2007, pp. 233-242.

[3] A. Chadwick and C. May, "Interaction between States and Citizens in the Age of the Internet:"e-Government" in the United States, Britain, and the European Union", Governance, 16 (2), 2003, pp. 271-300.

[4] C.C. Hood and H.Z. Margetts, The tools of government in the digital age: Macmillan International Higher Education, 2007.

[5] J. Clifton, D. Díaz Fuentes, and G. Llamosas García, "ICT-enabled co-production of public services: Barriers and enablers. A systematic review", Information Polity, (Preprint), 2020, pp. 1-24.

[6] H.J. Scholl, "Five trends that matter: Challenges to 21st century electronic government", Information Polity, 17 (3, 4), 2012, pp. 317-327.

[7] A. Cordella and A. Paletti, "ICTs and value creation in public sector: Manufacturing logic vs service logic", Information Polity, 23 (2), 2018, pp. 125-141.

[8] D.E. Luna, et al., "Digital governance and public value creation at the state level", Information Polity, $20(2,3)$, 2015, pp. 167-182.

[9] F. Contini and G.F. Lanzara, (Eds.), The Circulation of Agency in E-Justice: Interoperability and Infrastructures for European Transborder Judicial Proceedings, Springer: Dordrecht, 2014.

[10] M. Velicogna and G. Lupo, "ICT Development and Business Process Modelling in the Legal Domain: The Experience of e-CODEX", European Quarterly of Political Attitudes and Mentalities, 8 (1), 2019, pp. 22-47. 
[11] E.C. Page, "The civil servant as legislator: law making in British administration", Public administration, 81 (4), 2003, pp. 651-679.

[12] L.H. Silberman, "Chevron-The Intersection of Law \& Policy”, Geo. Wash. L. Rev., 58 1989, pp. 821.

[13] C. Reed and A. Murray, Rethinking the jurisprudence of cyberspace, Cheltenham: Edward Elgar Publishing, 2018.

[14] B. van den Berg and R.E. Leenes, "Abort, retry, fail: scoping techno-regulation and other techno-effects", in Hildebrandt, M. and J. Gaakeer (Eds.), "Human law and computer law: comparative perspectives", Springer: Dordrecht, pp. 67-87.

[15] A. Murray, The regulation of cyberspace: control in the online environment, Cavendish: Routledge, 2007.

[16] J. Van den Hoven, S. Miller, and T. Pogge, "The design turn in applied ethics", Designing in ethics, 2017, pp. 11-31.

[17] L. Floridi and J.W. Sanders, "On the morality of artificial agents", Minds and machines, 14 (3), 2004, pp. 349-379.

[18] B.D. Mittelstadt and L. Floridi, "The ethics of big data: current and foreseeable issues in biomedical contexts", The ethics of biomedical big data, 2016, pp. 445-480.

[19] G.F. Lanzara, "Building digital institutions: ICT and the rise of assemblages in government", in Contini, F. and G.F. Lanzara (Eds.), "ICT and Innovation in the Public Sector: European Studies in the making of eGovernment", Palgrave MacMillan: London: United Kingdom, pp. 9-48.

[20] K. Tranter, "The laws of technology and the technology of law", Griffith Law Review, 20 (4), 2011, pp. 753-762.

[21] R. Brownsword, Law, Technology and Society: Reimagining the Regulatory Environment, London: Routledge, 2019.

[22] M. Hildebrandt, Law for Computer Scientists and Other Folk, Oxford: Oxford University Press, 2020.

[23] M. Hildebrandt and B. van den Berg, (Eds.), Information, freedom and property: The philosophy of law meets the philosophy of technology, Routledge: London, 2016.

[24] R. Mohr and F. Contini, "Reassembling the Legal: 'The Wonders of Modern Science' in Court-Related Proceedings", Griffith Law Review, 20 (4), 2011, pp. 9941019.

[25] O. Hanseth and K. Lyytinen, "Design theory for dynamic complexity in information infrastructures: the case of building internet", Journal of Information Technology, 25 2010, pp. 1-19.

[26] J. Zittrain, The future of the internet - and how to stop it, Yale: Yale University Press, 2008.

[27] E.G. Anderson Jr, G.G. Parker, and B. Tan, "Platform performance investment in the presence of network externalities", Information Systems Research, 25 (1), 2014, pp. 152-172.

[28] J. Burrell, "How the machine 'thinks': Understanding opacity in machine learning algorithms", Big Data \& Society, 3 (1), 2016, pp. 1-12.

[29] D.S. Evans, "Governing Bad Behavior by Users of Multi-Sided Platforms", Berkeley Technology Law Journal, 27 (2), 2012, pp. 1201-1250.

[30] F. Gualdi and A. Cordella, "Artificial intelligence and decision-making: The question of accountability", in
Proceedings of the 54th Hawaii International Conference on System Sciences. 2021,

[31] A. Cordella and F. Gualdi, "Law, technology and policies: a complex negotiation to generate value", in Proceedings of the 2019 3rd International Conference on Ecommerce, E-Business and E-Government. 2019, Lyon

[32] M. Bovens and S. Zouridis, "From street-level to system-level bureaucracies: How information and communication technology is transforming administrative discretion and constitutional control", Public Administration Review, 62 (2), 2002, pp. 174-184.

[33] J. Kallinikos, "The order of technology: Complexity and control in a connected world", Information \& Organization, 15 (3), 2005, pp. 185-202.

[34] J. Kallinikos, "Institutional complexity and functional simplification: the case of money claim online service in England and Wales", in Contini, F. and G.F. Lanzara (Eds.), "Ict and Innovation in the Public Sector: European Studies in the making of eGovernment", Palgrave MacMillan: London, pp. 174-210.

[35] N. Luhmann, Risk: A Sociological Theory, New Brunswick, N.J.: Aldine Transaction, 2005.

[36] R.K. Yin, Case study research and applications : design and methods, Los Angeles: SAGE, 2018.

[37] P. Baxter and S. Jack, "Qualitative case study methodology: Study design and implementation for novice researchers", The Qualitative Report, 13 (4), 2012, pp. 544559.

[38] D. Carnevali, "Great Success that Was on the Brink of Failure: The Case of a Techno-Legal Assemblage in the" Civil Trial On-Line" System in Italy", European Quarterly of Political Attitudes and Mentalities, 8 (2), 2019, pp. 2135.

[39] A. Rossetti, "PCT e nuovo CAD: figlio minore e trascurato", 15/02/2016, Last Access: 10/06/2020, Available from: https://www.forumpa.it/pa-digitale/pct-e-nuovo-cadfiglio-minore-e-trascurato/.

[40] L. Petrucci, "Il processo telematico e la lezione del Gattopardo", Questione Giustizia, 23/10/2017, Last Access: 11/04/2021, Available from: https://www.questionegiustizia.it/articolo/il-processotelematico-e-la-lezione-del-gattopardo_23-10-2017.php.

[41] F. Consolandi, "Tutti i problemi del nuovo Cad per la Giustizia digitale: la privacy vince sulla conoscenza", 12/02/2016, Last Access: 16/05/2021, Available from: https://www.forumpa.it/pa-digitale/tutti-i-problemi-delnuovo-cad-per-la-giustizia-digitale-la-privacy-vince-sullaconoscenza/.

[42] A. Cordella and F. Iannacci, "Information systems in the public sector: The e-Government enactment framework", The Journal of Strategic Information Systems, 19 (1), 2010, pp. 52-66. 